\title{
Wnvironmental Conservation
}

\section{INSTRUCTIONS FOR AUTHORS}

\begin{abstract}
-Manuscripts' must be original, in clear English, and not currently under consideration for publicalion elsewhere. Three copies should be submitted - including I or 2 on light airmail paper - in double-spaced typing on one side only of consecutively numbered pages of uniform size not more than $30 \mathrm{~cm}$ in length, leaving adequate margins. Survey and research papers should preferably be between 4,000 and 7,000 words in length and only exceed 8,000 words (including references etc.) if subsidized. Other contributions should not exceed 3,000 words and those of more than onefifth that length or two typed pages should be suitably subdivided with a brief heading to each section. Primary sub-headings in major papers should be centred, whereas any secondary ones should be brought out to the lefthand margin. Footnotes are, in general, deprecated except when inserted for editorial exposition. Headings of items for the sections 'Conferences \& Meetings' and 'Book Reviews \& Notices' must be in the style of the Journal - the former naming the occasion, place, and dates, and the latter complete with publisher and place, preliminary and other page-spreads, then indication of any illustrations, all three dimensions in metric, price, and date of publication (which should normally be not earlier than the preceding calendar year). The optimum length in both these categories is $300-400$ words, though up to double the latter may be allowed for items of outstanding importance.
\end{abstract}

Style of Writing should be direct and concise, with punctuation etc according to The Oxford Dictionary for Writers and Editors and spellings according to the Oxford English Dictionary. Dates should be in the form " 1 March 1974 and single quotes should be used throughout (except for the use of double quotes within quotes). Any symbols or abbreviations employed should be the conventional ones, with omission of all unnecessary full stops (periods). If other than metric units are used, the metric equivalents must be inserted in parentheses after them. Submissions should be as neat and "clean" as possible, and checked meticulously for errors and inconsistencies: always keep a fully corrected copy for reference in editorial correspondence and in case of loss of the original.

Tables may be included in the main body of the manuscript but must in all cases be numbered consecutively with roman numerals, and appropriately headed. They should be kept as simple and short as possible, though longe Appendixes may exceptionally be allowed. All illustrations - whether photographs, drawings, maps (always with scales!), or graphs - are to be numbered in a single sequence as 'Fig. 1', 'Fig. 2', etc., and so referred to in the text. Each must be clearly captioned, with acknowledgement of source when necessary, the captions being typed consecutively on a separate sheet at the and of the paper.

Scientific Names of plant and animal genera, subgenera, species, and lower taxa. need to be used for precision and underlined for italic, specific and lower epithets being written with a 'small' initial letter; the initial letters of precise (but not group) English and other vernacular names should, however, be capitalized. Nomenclature should be in accordance with the appropriate international code, and the publishing authority may if desired be given the first time a name is mentioned, though in that event consistency should be maintained with other names throughout the paper. Ecological and other scientific term; should either follow reasonably standardized usage or be defined the first time they are employed in a paper-throughout which this meaning alone should be used.

With our very wide readership, verbal descriptions are much preferred to complicated formulae and equations, which should be avoided so far as possible. Acronyms. if not universally familiar, should be spelt out the first time they are used in a paper.

Submission of major 'manuscripts' should be by 15 December, 15 March, 15 June, and 15 September, for consideration for the Spring, Summer, Autumn, and Winter issues, respectively, the absolute deadlines (particularly for brief news etc. items) being 15 January, 15 April, 15 July, and 15 October. As, however, extensive 'pre-editing' and correspondence are commonly necessary before an accepted paper is ready to go for typesetting, submission should be considerably earlier - to give a reasonable chance of publication in the issue of the following season if space allow's. All refereeing is strictly confidential unless a referee agrees to the release of his or her identity through the Editor, who then uses his discretion.

Titles of all papers should be as short as possible, inter alia for use as running headings. Those of research and survey papers are to be followed by the names of the Author or Authors (including preferred given name in fill and any further initial or initials, and followed by indications of any higher degrees and where obtained). Thereafter comes an indication of academic or other allegiance and/or senior post or posts held and full address underlined for italic. Instead of the customary Abstract at the beginning, a SUMMARY is required at the end of each paper, to recapitulate and emphasize its main points. This should preferably not exceed about 400 words in length, in 2 or 3 paragraphs, and follow any ACKNOWLEDGEMENTS. It should be 'self-contained' in being easily understandable without reference to the general text. Short communications etc. do not need a Summary, and the 'signature' and address of their Authors should be placed at the end, after any References.
Literature References are treated according to the Harvard System, with the Author (or Authors connected with an ampersand if two, or with 'et al.' replacing surnames after the first if more than two), and indicating the year of publication in parentheses: e.g. '(Smith, 1973)' or 'according to Smith (1973)'. References should be cited as 'in press' (not by date) only when already accepted for publication, the journal or publisher and place being named. Whereas in short communications any references may if desired be given in parentheses in the text, normally — and always in long papers they are to be collected together in a list headed 'REFERENCES', alphabetically arranged by [first] Authors' surnames, but unnumbered, at the end of the paper. There, all Authors' names and initials are required, followed by the date of publication (in parentheses), and then the full title of the paper (with capitalization of initials only where required). There follow the title of the periodical, underlined for italic and given in full or contracted consistently, then the volume number in bold-face (with number of part, if desired, closed up in parentheses), then the page-spread in the form 'pp. 321-5', and finally an indication of 'illustr.' (if it is in any way).

For books and other 'separate' publications, the full title is given, upholding any capitals and underlining for italic, and then the name of the publisher and place or places of publication, followed by full details of pages in the form of e.g. 'xxvii +294 pp., illustr.' (if it is). In symposium volumes the page-spread of the individual paper should be given before 'in' and then the title of the book and other full details. Examples are to be found in any issue of Environmental Conservation. Authors must ensure that their references are accurately cited: the Editor will be apt to refer back any which appear incorrect or incomplete, or to reject any submission in which errors are so frequent as to raise doubts regarding its general reliability.

Illustrations are welcomed in limited numbers when really vivid and meaningful. Submission of single copies will suffice if necessary but all must be identified by at least the [first] Author's surname and then figure number lightly pencilled on the back. Maps and other line drawings should be in a form ready for reproduction without redrawing, with stencilled or printed lettering and lined or large-dotted shading, and suitable for reduction either to $8.1 \mathrm{~cm}$ (single-column) or occasionally $16.5 \mathrm{~cm}$ (double-column) width. Photographs should normally be black-and-white glossy prints showing clear details and adequate contrast. If not evident from some feature of known or indicated dimensions, the scale of all illustrations should (for maps must) be indicated either by a statement in the caption or by a graduated line marked in the appropriate metric unit. Return of originals if desired should be indicated clearly but cannot be guaranteed, though a reminder when proofs are returned should be a safeguard. Costs of coloured illustrations can be quoted by our Printer, whose address is given near the end of the penultimate paragraph below and also at the foot of the back cover of each issue of the Journal.

Proofs will be sent to the Author (or the first-named alone if more than one) of each signed paper or other contribution. They will be accompanied by an addressed sticky label for speedy return to the Editor, who reserves the right to 'pass for press' if Authors' corrections are not received back promptly. A green form for ordering offprints (see next paragraph), or reprints with no extraneous material but covers printed as desired, will be enclosed with the proofs, and, together with a bank cheque or International Money Order for the appropriate amount (made out to the Foundation for Environmental Conservation in US dollars), should be returned to the Editor with the corrected proofs. In cases of plural authorship, Authors receiving proofs are asked to check with their Co-authors concerning corrections and ordering of reprints. In view of the extremely high and ever-rising costs of printing, and particularly of altering set pages, it is requested that only necessary corrections be made in proof, although, exceptionally, suggestions for alterations or brief additions may be entertained if space allows.

Offprints \& Reprints: Our practice for many years was to send 50 free Offprints of his or her paper to the Author (or the first-named if more than one) of each signed paper or short communication etc. provided they were claimed on the Ordering Form accompanying the proofs*, but owing finally to extensive pirating this was discontinued as from the first issue of Vol. 20 (Spring 1993). [The 'last straw' was to be informed in writing from a major multinational organization that the free reprints were desired as 'It will save us the nuisance of photocopying'!]. However, starting with the generosity of our Foundation Printer, it has been possible to continue virtually unchanged for many years our prices to Authors of Offprints and the more costly Reprints with printed covers, as indicated in the green form accompanying proofs of their contributions. These prices need now to be in US dollars, in which our Swiss Bankers (Pictet \& Cie, Geneva) have warned us all cheques and money orders should be received in order to avoid delays and other complications (including extra charges made by foreign agents which can be quite devastating and even exceed the value of the item!). Questions regarding reprints (such as of unsigned items), possible loss, quotations for especially large orders or coloured illustrations, etc., should be addressed to our Foundation Printer, Mr Gilbert-E. Huguet, 43 Route de Loëx, 1213 Onex/Geneva, Switzerland - not to the Editor or owning Foundation.

The Editor wishes to indicate his availability for consultation but to emphasize that the more closely the above instructions are adhered to in the preparation and submission of a manuscript, the speedier will be its consideration and, if accepted, publication. For general style it is recommended that any recent issue of the Journal be consulted.

* Saving from not sending out free offprints automatically from some years ago has helped us to give at least one 'Best Paper' prize each year ever since. 


\section{Ornvironmental Conservation}

THE SCIENTIFIC JOURNAL DEVOTED TO GLOBAL SURVIVAL

Volume 21, Nr 2 - Summer 1994

CONTENTS

Editorial Section:

Pages

Editorial: Biosphere Day, Prizes, and Clubs ...................................................... 97

Publication Notice: Population and Global Security (Limited Geneva Edition) ........................... 98

Guest Editorial: Environment and Disease: Ever-growing Concern, by Dr Lute Bos ..................... 99-102

Guest Comment: Trouble in the Cabbage-patch, by Professor Denis F. Owen ........................ 102-3

Updated Notice of Publications ................................................................. 104

Main Papers:

Predictions for Cairo: A Reaffirmation, A Reversal, A Realignment, and A Refusal, by Adil Najam ........

Population, Desertification, and Migration, by Dr Arthur H. Westing (5 tables) ..........................

The Role of Local People in the Successful Maintenance of Protected Areas in Madagascar, by Joanna

C. Durbin \& Jonny A. Ralambo (2 figs)

$105-9$

$110-4$

$\& 109$

Environmental Deterioration Resulting from Ski-resort Construction in Japan, by Dr Shiro Tsuyuzaki

(5 figs and table)

$115-20$

Studies on the Topsoil of an Underground Coal-mining Project, by Nishit K. Kundu \& Dr Mrinal K.

Ghose (4 figs and 6 tables)

Margrethe-Kog and the Artificial Lagoon: Evaluation of a Habitat Restoration Project in the Danish Wadden Sea, by Knud Falk, Henning Nøhr \& Lars Maltha Rasmussen (6 figs and 2 tables) ............

Conservation Awareness through an Environmental Education Programme in the Atlantic Forest of Brazil, by Suzana M. Padua (2 figs and 4 tables)

An Attempt to Predict Which Amazonian Tree Species May Be Threatened by Logging Activities, by Adriana M.Z. Martini, Nelson de Rosa \& Dr Christopher Uhl (2 figs, table, and Annex)

Short Communications \& Reports:

The Fine Structure of the Solar Spectrum and Evolution of The Biosphere, by Professor Petr P. Fedchenko, Academician Kyrill Y. Kondratyev \& Professor Hartmut Grassl ...........................

A Case-study on Biodiversity: Pesticide Engendering of Ecological Imbalance and Resultant Environmental Consequences, by Dr Alungal N. Balchand (map)

The Los Santos Forest Reserve: A Buffer Zone Vital for the Costa Rican La Amistad Biosphere Reser$v e$, by Maarten Kappelle \& Marta E. Juárez (map)

Death of a Lake: Lac Noir in Northeastern Algeria, by Gérard de Belair \& Dr Bondjema Samraoui (6 figs)

Arun III: Nepal's Controversial Hydroelectric Project, by Gopal Siwakoki ........................

The Foundation for Environmental Awareness, by Professor Gunavant M. Oza ......................

Every Day a Biosphere Day: Path for Sustainability, by Premlata Oza \& Professor Gunavant M. Oza (4 figs) ..................................

Optimum Human Population About One-third of Present Number, by Peter Rapalus ................

Small Islands Most Vulnerable to Natural Disasters
Pages

$164-6$

$166-9$

$169-72$

Conferences \& Meetings:

Reports (in chronological order) by Professor Roger H. Charlier, Professor S. Fred Singer, Professor John L. Cloudsley-Thompson, Dr Denis A. Saunders \& John L. Craig, Dr Arthur H. Westing,

The Significance of Urban Nature, by Gerald F.M Dawe \& Keith Grice .......................... IIASA Goes Global, by Elisabeth Krippl

$178-9$ Migration, communicated by Dr Arthur $\mathrm{H}$. Westing .........................................

Gold Medal for International Corporate Environmental Achievement, by Ann Venardos ............

Francis L. Dale: A Personal Reflection, by $\mathrm{Dr}$ Arthur H. Purcell

Francis L. Dale: Further Appreciation, by Nicholas

$179-81$

$181-2$

182 and Sharon Griffiths; Important Prospects by Lies Dobkins and Dr Brian D. Clark ......................

$173-4$

Book Reviews \& Notices:

$174-6$

176-7

$177-8$
Book Reviews by Professor Elisabeth Koutaissoff, Dr E. Barton Worthington, Professor Garry W. Trompf, Professor Roger H. Charlier, and Professor Richard Evans Schultes Polunin (fig.) ................................

All rights reserved. With the exception of photocopying or other reproduction with due acknowledgement of their own items only by Authors or Co-authors in the Conferences \& Meetings and Reviews \& Notices sections, no integral part of this publication may be reproduced, stored in a retrieval system, or transmitted, in any form or by any means - electronic, mechanical, photocopying, recording, or otherwise - without permission in writing from the Editor or the copyright-owning Foundation. Quotation of brief passages with due citation is, however, welcomed. 